\title{
The Health Equity Dimensions of Urban Food Systems
}

\author{
Jane Dixon, Abiud M. Omwega, Sharon Friel, Cate Burns, \\ Kelly Donati, and Rachel Carlisle
}

\begin{abstract}
There is increasing recognition that the nutrition transition sweeping the world's cities is multifaceted. Urban food and nutrition systems are beginning to share similar features, including an increase in dietary diversity, a convergence toward "Western-style" diets rich in fat and refined carbohydrate and within-country bifurcation of food supplies and dietary conventions. Unequal access to the available dietary diversity, calories, and gastronomically satisfying eating experience leads to nutritional inequalities and diet-related health inequities in rich and poor cities alike. Understanding the determinants of inequalities in food security and nutritional quality is a precondition for developing preventive policy responses. Finding common solutions to under-and overnutrition is required, the first step of which is poverty eradication through creating livelihood strategies. In many cities, thousands of positions of paid employment could be created through the establishment of sustainable and self-sufficient local food systems, including urban agriculture and food processing initiatives, food distribution centers, healthy food market services, and urban planning that provides for multiple modes of transport to food outlets. Greater engagement with the food supply may dispel many of the food anxieties affluent consumers are experiencing.
\end{abstract}

KEYWORDS Urban food and nutrition systems, Health inequities, Nutrition transition, Social determinants of nutrition, Urban agriculture and food distribution, Urban nutrition interventions

\section{INTRODUCTION}

Half of the world's population live in large settlements, often on food-producing lands and in political environments where governments have traded off agricultural self-sufficiency for an industrial economy fuelled by the lure of food exports and food import substitution. ${ }^{1}$ As painfully slow advances are made to reduce the numbers who are underweight, there has been a rapid escalation in the numbers

Dixon is with the National Centre for Epidemiology and Population Health, Australian National University, Acton, 0200, Australia; Omwega is with the Department of Food Science, Nutrition and Technology, University of Nairobi, P.O. Box 442-00605, Uthiru, Nairobi, Kenya; Friel is with the International Institute for Society and Health, University College London, 1-19 Torrington Place, London, WC1E 6BT, England; Burns is with the School of Public Health, Deakin University, Burnwood, Victoria, Australia; Donati is with the School of Global Studies, Social Science and Planning, Royal Melbourne Institute of Technology University, LaTrobe Street Melbourne, Victoria, Australia; Carlisle is with the Physical Activity, National Heart Foundation of Australia (Victorian Division), 411 King Street, West Melbourne, Victoria 3003, Australia.

Correspondence: Jane Dixon, National Centre for Epidemiology and Population Health, Australian National University, Acton, 0200, Australia. (E-mail: jane.dixon@anu.edu.au) 
who are overweight and obese, a risk factor for numerous chronic noncommunicable diseases. ${ }^{2}$ City inhabitants are at particular risk of both under- and overnutrition because of their reliance on a commercial food supply, access to which requires income from wages.

This paper focuses on the dynamics of national food and nutrition systems as they impact on the health inequities present within city populations. We synthesize a broad sweep of literature to develop a theoretical map of the food system determinants of health inequities and nominate seven key determinants of urban nutrition status. To highlight the complex set of relationships that underpin food and nutrition systems in countries at varying stages of industrialization-postindustrial, industrial, and industrializing - we briefly describe the situations of three cities: Melbourne, Bangkok, and Nairobi (see Dixon et al. ${ }^{3}$ for greater detail-www.who.or.jp). Reference to different stages of industrialization reflects more accurately the economic transition underway globally than the terms "developed/developing" countries.

\section{THE URBAN NUTRITION TRANSITION: CONVERGENCE, DIVERGENCE, AND INEQUALITY BECAUSE OF BIFURCATION}

Approximately 800 million people are food-insecure and at risk of undernutrition and underweight. "Of these, 95\% are in middle- and low-income countries (and around $60 \%$ of these are in Asia." ${ }^{4}$ However, since the 1970 s, there has been a generalized nutrition transition characterized by greater dietary diversity and a shift toward "Western-style diets" of meat, dairy, less complex carbohydrates, and reduced fruit and vegetable intakes. The amount of energy available for consumption has increased, with the highest levels being in the Middle East, China, Latin America followed by the rest of Asia and Oceania. ${ }^{5}$ This situation is because of a host of factors, including the global trade in foods and technological revolutions in agriculture and food processing which mean that "[p]eople around the world can purchase more calories today for the same money as Western Europeans could decades ago at a similar gross domestic product level." ${ }^{6}$ Relatively easy access to caloric energy is a major contributor to the two billion adults estimated to be overweight and obese. ${ }^{7}$

The nutrition transition typically begins in cities because urbanization is accompanied by social and economic trends that encourage the transition. ${ }^{8-11}$

Demand side factors include:

- Higher incomes and higher levels of education;

- Women in paid employment, and itinerant male workers, demanding the outsourcing of home produced services;

- Younger populations who are socialized to accept variety and novelty; and

- Diverse population groups who are colocated, creating dynamic markets for niche (also known as status-positioning) products.

Supply side factors include:

- A food supply that is higher in fat content, sugar, and salt with higher volumes of meat, dairy, and alcohol;

- Prices of processed foods are lower relative to staple foods;

- Exposure to new trends through mass media advertising, imports, tourism, specialist producers, and distributors; and 
- The displacement of small family run stores/stalls by corporate food distributors, which encourage bulk purchases, special meal "deals," convenience foods, and "superized" portions.

Up to a certain stage of socioeconomic development, urban diets are considered to be more nutritious because "urban dwellers consume a more varied diet than their rural counterparts, richer in animal proteins, fats, and processed staple foods." ${ }^{12}$ In China, for example, the urban nutrition transition is well-established; per capita meat and fish consumption are significantly higher in urban areas, and urban grain consumption is three times lower than that in rural areas. ${ }^{13}$

The risk of overconsumption of energy increases with close proximity to markets and food processing sectors, ${ }^{12}$ whereas many of the urban poor do not benefit from the entire cornucopia because "the shift towards fast and convenience foods is also a shift away from fresh fruits and vegetables, pulses, potatoes and other roots and tubers towards a diet with increasing consumption of sugar, salt and fat in the diet." 9

Hawkes ${ }^{14}$ argues that analyses of the nutrition transition must acknowledge socioeconomic differentials to dietary changes. She notes that within industrializing countries, the diets of whole populations are converging toward a similar but limited mix of food groups with dietary diversity, or divergence, confined to wealthier and better educated groups. Unequal access to calories and diversity gives rise to inequities in nutrition status, with undernutrition being more common among the poor in industrializing cities, whereas in industrial cities the rising middle classes are at greater risk of overnutrition. The coexistence of under- and overweight individuals in the same household poses difficulties for interventions, with one estimate for China being $10 \%$ of households experiencing the double burden of malnutrition. ${ }^{9}$ Among the very poor, overnutrition can coincide with micronutrient deficiency. ${ }^{14}$

In the postindustrial country context, unequal access to dietary diversity has been characterized as a slow food-fast food binary. In this scenario, the wealthy consume diverse diets of unprocessed and local foods sourced from specialist providors, city farmers markets, and "wholefood" cafes and restaurants, whereas the majority rely on industrial and processed foods of varying nutritional quality sourced from supermarkets, fast food chains, and cafes that use short-order cooks to heat and serve mass-produced food. ${ }^{15,16}$

Sonnino and Marsden ${ }^{17}$ argue that these trends in diets are the result of "the contemporary food sector...bifurcating into two main 'zones' of production: standardized, specialized production processes responding to economic standards of efficiency and competitiveness on the one hand; localized, specialized production processes attempting to trade on the basis of environmental, nutritional, or health qualities on the other." The alternative food "zones" provide distinctive nutritional content and opportunities for food-related satisfaction and satiety. ${ }^{18,19}$

Driving the food zone based on standardized foods is a relatively small number of transnational corporations, as evidenced by the fact that in 2002, the ten largest food companies controlled $24 \%$ of global processed food sales. ${ }^{20}$ From their numerous country offices, field officers negotiate contracts with farmers and suppliers for highly prescribed quantities and qualities of product, which will enter global commodity chains (see illustrative case studies of African cocoa bean sourcing $^{21}$ and the global processed tomato industry). ${ }^{22}$ The global trade in fresh and processed foods is regulated less by governments and producer groups and 
more by international conventions, such as the Sanitary and Phyto-Sanitary agreement of the WTO, and initiatives such as the European Produce Working Group (comprised of 13 leading food retailers), which has protocols covering supply chain dynamics to ensure food safety. The global harmonization of food standards and retailer consortium domination of standards "reveal tensions between the goals of trade facilitation and the protection of public health," and can operate in favor of wealthy, urban consumers and against the livelihoods and health status of rural communities. ${ }^{23}$

In this way, the governance structures that regulate the international food trade alongside the national bifurcation of urban food systems are having significant impacts on health inequities. Given the critical importance of nutrition to early physical and cognitive development, children are especially vulnerable to the inequitable distribution of, and access to, food. Whereas there are significant urban-rural differences, with the prevalence of underweight among urban children less than among rural children, urban areas contain marked disparities, which can be greater than rural differentials. In urban areas of Latin America, the risk of stunting is estimated to be up to 10 times higher among the poorest children than for the wealthiest group. ${ }^{24}$

\section{CONCEPTUALIZING THE HEALTH INEQUITY IMPACTS OF URBAN FOOD SYSTEMS}

On the basis of the foregoing literatures, Figure 1 provides a theoretical schematic of the pathways linking globalization, urbanization, national food system

\section{URBAN SETTINGS, FOOD AND NUTRITION SYSTEMS, AND HEALTH INEQUITIES}

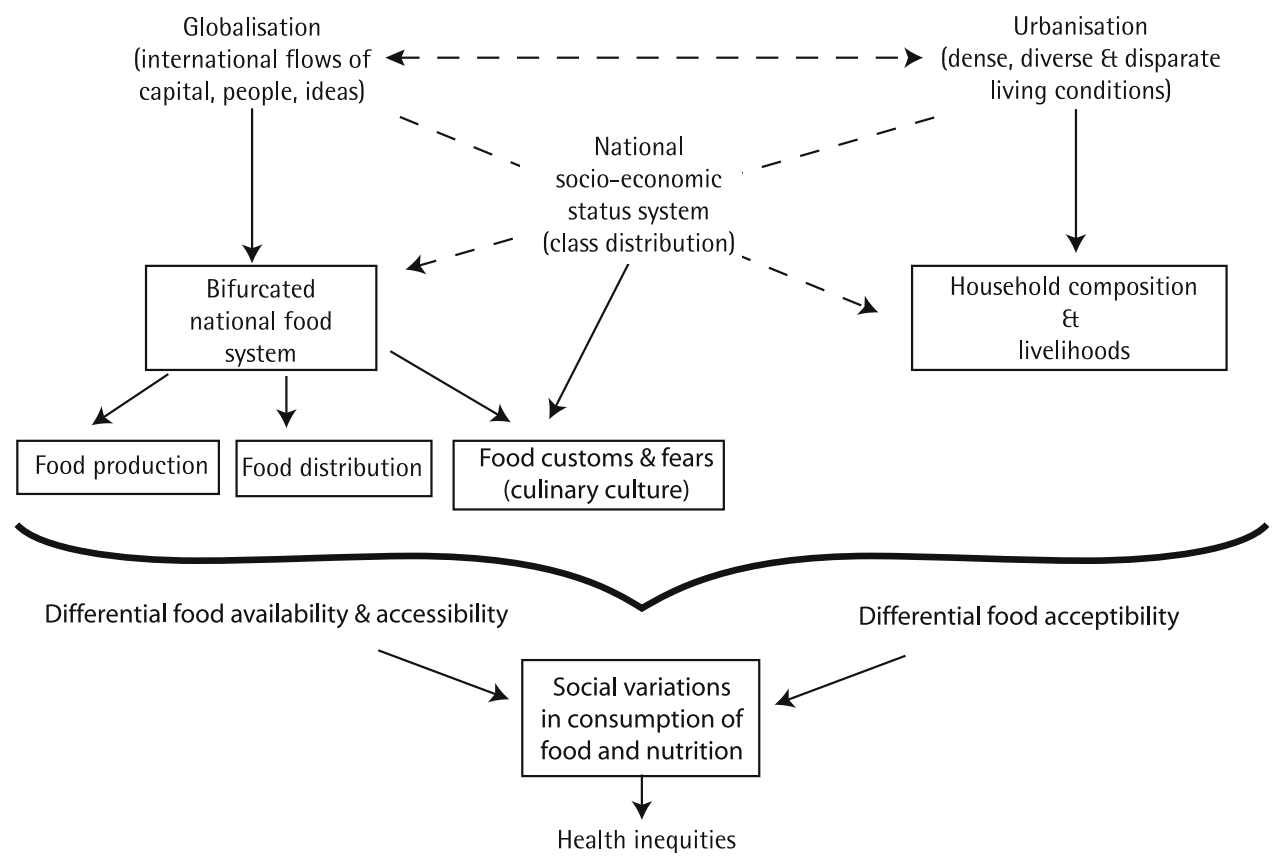

FIGURE 1. Pathways linking urban food and nutrition and health inequities. 
dynamics, and class composition to the differential availability, access, and acceptability of foods at the household level. Factors operating at these different levels codetermine the population's propensity to consume differential amounts of calories and types of nutrients, leading to inequities in the distribution of diet related diseases.

\section{THREE CITY CASE STUDIES}

Issues of food security and malnutrition in rich and poor cities are becoming more complex and differentiated. Because of a lack of comparative data, we illustrate the dynamics of three urban food systems before detailing the major structural determinants of diet-related health inequities.

\section{A. The industrializing city: Nairobi, Kenya}

Kenya is a low-income, food-deficit country with a GDP per capita of around U.S. $\$ 460^{25}$ and $49 \%$ of its urban population are poor. Approximately one third of the 33 million were estimated to be living in cities and towns in 1999. Although most rural migrants search for jobs to support their immediate families and dependants, many end up being unemployed or are casually hired in low-earning engagements with no job security. ${ }^{26}$ Inadequate provision of clean and safe water, poor sanitation, dwindling space both for housing and farming, and lack of policy on urban farming is making food in cities a scarce commodity because of a reliance on declining rural areas for food. ${ }^{27,28}$

In Nairobi, Kenya's capital, the poor constitute $55 \%$ of the population although they occupy only $5 \%$ of the total residential land area. Poverty and a reduction in agricultural production means that about $47 \%$ of the population is food-insecure. As in many parts of Africa, low- and medium-income households spend about three-quarters of their income on food. The high level of HIV infection (1.2 to 1.5 million 15-49 year old) further reduces household ability to produce and buy food, and HIV prevalence is higher in cities. ${ }^{29}$

The major dietary issue for Nairobi is food insecurity, where people do not have consistent physical, social, and economic access to sufficient, safe, and nutritious food to meet their dietary requirements and for an active and healthy life. ${ }^{30}$ In urban areas, food is usually available but a nutritionally adequate diet is too costly for at least one third of households. ${ }^{31}$

In a context of low national GDP, undernutrition is the major result of food insecurity. Twenty percent of Kenyan children are underweight whereas $31 \%$ are stunted. Anemia and vitamin A deficiencies are prevalent among children and women. ${ }^{32}$

\section{B. The industrialized city: Bangkok, Thailand}

Thailand is Southeast Asia's second largest economy, and has the region's highest female labor force participation rates. For many years, successive Thai governments have discriminated against agriculture in favor of capital-intensive manufacturing, including food processing. This policy shift strengthened after the 1997 economic crash, with the privatization of state enterprises. As a "New Agricultural Country," Thailand has moved from the export of raw commodities like rice to the production and export of higher value foods for Western consumers, such as farmed seafood. ${ }^{33}$ In 1990, 70\% of the labor force was employed in agriculture/fishing falling to $45 \%$ in $2002 .{ }^{34}$ 
Approximately $20 \%$ of Thailand's 65 million population lives in Bangkok, and per capita income differentials between the national capital and the rest of Thailand remain wide: 229,000 Bhat per annum compared to 74,600 Bhat (U.S. \$2,225). For the northeast agricultural region the income disparities are even wider: per capita income is one third of the national average. ${ }^{35}$

Bangkok has become like any other modern Asian metropolis with a variety of retail forms. ${ }^{36}$ It contains $70 \%$ of the country's supermarkets and superstores, ${ }^{37}$ whereas the rest of Thailand maintains its Thai-Chinese shop houses, street stalls, and wet markets. Urban wet markets cannot compete with supermarkets on price or perceived food safety, but they continue to cater for the Thai population considered poor, of low education (55\% of population in 2000 ), and who value a traditional diet.

The major dietary issues include undernutrition in rural areas, and growing overnutrition/obesity, especially among children. Even in the least prosperous region of Thailand, the northeast, the prevalence of obesity is high among 7- to 9year-old schoolchildren, being $10.8 \%$ in 2000. Children from higher income and educated parents are particularly at risk. ${ }^{38}$

C. The postindustrial city: Melbourne, Australia

Australia is the world's most urban nation (i.e., ratio of urban to rural population is disproportionately high). Australia has a population of 20 million people, and per capita GDP was U.S. $\$ 25,353$ in $2003 .{ }^{39}$ More than $75 \%$ of Australian women with families have paid employment, and nearly $27 \%$ of household food expenditure is on takeaway, fast foods, and restaurant foods. On average 13\% of total energy intake in the Australian diet comes from foods prepared outside the home. ${ }^{40}$ In some households this can be as high as $60 \%$.

Melbourne, the capital of Victoria, has a population of 3.5 million people. It is known as a service and cultural arts center, with a strong presence of head offices for national and transnational offices, including supermarket chains and agricultural producers and processors. It is Australia's biggest contributor to dairy foods and processed fruits exports.

There are numerous signs of a bifurcated food system. Sales of organic foods increased tenfold between 1990-2000, ${ }^{39}$ whereas sales of low cost home brand supermarket items have grown by $30 \%$. According to UK research, but applicable to Australia, there can be marked variations in salt and sugar in similar products between "upmarket" chains and low-income chains. ${ }^{41}$

Australia experiences the full range of nutritional issues, namely:

Food Insecurity Specific nutrient deficiencies are present among indigenous, migrant, and elderly populations. ${ }^{42}$ The health effects of poor nutrition, including low birth weight, contribute to a life expectancy discrepancy of 20 years between indigenous and nonindigenous populations. ${ }^{43}$ In car-dominated cities, access to a car and food are related because the cheaper, healthier food outlets are in regional shopping centers. In Melbourne the lack of a car can reduce food access by $50 \%{ }^{44}$

Overnutrition Australians are among the most overweight and obese populations in the developed world. ${ }^{45}$ Obesity is more prevalent among poorer women and among richer men. ${ }^{46}$

Ontological Insecurity The decline of traditional culinary cultures based around seasonality, locality, and self-sufficiency has encouraged a state of ontological 
insecurity among postindustrial eaters. ${ }^{47}$ There is widespread anxiety among Australian consumers regarding a healthy $\operatorname{diet}^{48}$ and a plethora of competing sources of dietary advice.

\section{NATIONAL- AND HOUSEHOLD-LEVEL DETERMINANTS}

Based on a further synthesis of relevant literatures from four fields-nutrition science, development economics, food sociology and public health-we have identified seven major national and household level determinants of urban nutritional inequalities. Each is described in more detail in Dixon et al. ${ }^{3}$

1. Decline in national food self-sufficiency

In many countries, governments are withdrawing support from their agricultural sectors in favor of manufacturing and service sectors, and are overseeing the decline of peasant agriculture and a rise in agribusiness. ${ }^{1}$ This development model encourages the relocation of agricultural production from food-producing lands to allow urban and industrial expansion, and encourages the entry of Foreign Direct Investment to increase export capacity for value added foods. The model undermines the economic viability and physical sustainability of rural towns and villages. The consequent rise of rural poverty, in turn, exacerbates the growth of cities while the diminution in agricultural production for local consumption encourages food imports.

2. Displacement of local food retailers, encouraged by marketplace activities of corporate chains

Transformations in agriculture are being exacerbated and encouraged by trends in food vending. The phasing out of fresh produce markets, largely because of urban development pressures and the entry of supermarket and convenience store chains, diminishes food access for poorer communities. Furthermore, street vendors in industrializing cities comprise a significant employment generator, with one survey of 334 vendors in Accra, Ghana, indicating that the street food sector employed 60,000 people, with an estimated annual turnover of more than U.S. \$100 million. ${ }^{49}$ For some subpopulations (e.g., men without families and kitchenless households), street vendors are an important source of adequate nutrition. When these types of food outlet disappear, low-income groups risk not being able to afford regular meals.

3. Global food safety policies that impact negatively on small food producers, retailers, and poorer consumers

Food safety concerns operate at two levels: the health of the local community and nationally in a context of global commodity trade. For industrializing countries, the imposition of international agency and corporate food standards means that only the most sophisticated firms have the capacity to meet export market requirements, forcing smaller firms to close. Food that does not meet export standards may be "dumped" on local people. This practice complicates food security because "Ensuring the quality and safety of food is...an essential consideration in any food security program." 50

In the absence of street food sector food hygiene programs and facilities, an unintended byproduct of increasingly stringent international food standards, devised in part to satisfy wealthy consumer and tourist demands, can be to close down local food processors and vendors. 
4. Food system dynamics that favor processed, high energy foods

Producer subsidies, consumer demand for cheap food, and high levels of Foreign Direct Investment in food processing firms and convenience food chains encourages the production of high energy foods. ${ }^{13}$ The intensification of meat and processed food commodity chains, through corporate integration of farming and retailing operations, leads to higher volumes and lowers prices, ${ }^{51}$ encouraging overconsumption.

5. Loss of livelihood options in local food systems

Whereas the expansion of food processing capacity generates jobs (trend 4), livelihood options for millions of people are diminished through trends 1 to 3 . Reliable flows of household income are required for consistent access to nutritious foods in the cities, and the national-level changes described above are having negative livelihood impacts on large numbers of informal and small food producers and traders. Wet market stallholders and street vendors, principally women, lose income as their outlets disappear and the subsequent rise of income inequity acts with food insecurity to exacerbate diet-related health inequities.

6. Urban planning and car transport

Urban planning has contributed to diet-related disease and to health inequities through its support for automobility, ${ }^{51}$ and the synchronicity between cars and food outlets. ${ }^{15}$ Urban fresh food outlets will increasingly disappear as corridors for private vehicles receive planning support over more active forms of transport

7. Multiple sources of advice fuels consumer food anxieties

A move away from customary diets brings widespread consumer confusion and anxieties about food; and a psychosocial state of ontological insecurity appears to be associated with the rise in obesity. ${ }^{19}$ Because of the myriad of food choices that are aggressively marketed in modern cities, and the growth in competing sources of nutrition advice, ${ }^{53}$ many cities have a cultural form of food insecurity.

\section{INTERVENING TO DISRUPT THE SEVEN DETERMINANTS}

Determinants 1 to 4 apply to cities at the three stages of industrialization, whereas determinant 5 is most applicable to industrializing cities, determinant 6 to industrializing and postindustrial cities, and determinant 7 applies largely to postindustrial cities. Determinants 1 to 5 result from national government deregulation of financial and commodity markets combined with the activities of global food manufacturing and retailing corporations, within a context of ongoing state regulation of agriculture via producer subsidies by North American and European nations. Determinant 6 is partly a result of mass movements of rural people into cities in search of employment, aggressive lobbying efforts by automobile producers, and fiscal crises of cities leading to underinvestments in active transport infrastructures. ${ }^{51}$ Determinant 7 is the inevitable consequence and embodiment of the other determinants because they combine to remove consumers physically and culturally from their food supply. Countries that cling to their culinary traditions (France and Japan) exhibit lower levels of overnutrition and have populations who express pleasure in food. ${ }^{52}$

Any substantial effort to interrupt the pathways depicted in Figure 1 will necessarily involve national governments renegotiating world food production and trade rules. In the meantime, cities can embark upon building and strengthening urban food systems to improve nutrition, increase food sector employment, strengthen food safety for local consumers, and reestablish the sociophysical bonds between people and their food supply. The following initiatives are described in 
greater detail in Dixon et al. ${ }^{3}$ Most are partnerships between governments, locally owned small and medium enterprises, and civil society. Some analysts believe that food and agricultural social movements have a pivotal role to play in building socially and environmentally sustainable food and agriculture systems. ${ }^{54}$

In relation to food production and processing, the Nairobi and Environs Food Security, Agriculture and Livestock Forum has sponsored training courses on urban agriculture and livestock keeping, with gains in the availability and affordability of food, urban farmer incomes, and the cleaning and greening of the city in which it has been piloted. Indigenous people and governments of three South American countries have worked with the Italian-based Slow Food Movement to support the growth of local food economies, and to provide traditional foods of superior nutritional value.

Ninety kilometers north of Bangkok, the city of Sam Chuk has restored its major food and smallgoods market with the assistance of the Community Architects for Shelter and Environment, ensuring the sustainability of trader livelihoods while attracting tourists. Bugurini Market in Dar es Salaam has become an exemplar for WHO's Healthy Marketplace program, by introducing best practices to prevent and control foodborne hazards, again ensuring the survival of fresh food markets in that city. And in the postindustrial context, the London Development Agency has conducted a feasibility study to establish a sustainable food distribution hub to supply independent food retailers, restaurants, and citybased institutions.

An increasing number of cities are adopting policies to limit car transport and to encourage alternative forms of mobility, but few have developed a comprehensive strategy to make population health a key planning principle. In Melbourne, the National Heart Foundation has developed with the Planning Institute of Australia (Victoria branch) a set of design considerations to promote walking, cycling, and public transport use. Implementation will improve people's access to healthy food options.

\section{CONCLUSION}

Rather than a single nutrition transition, urban food and nutrition systems are characterized by a complex convergence-divergence in increasing caloric energy and dietary diversity as well as a bifurcation in dietary sources, especially within more affluent cities. These trends are encouraging a maldistribution of global dietary energy and nutrition intake, which is reflected in inequalities in overnutrition, undernutrition, and diet-related health inequities.

Feeding city populations equitably cannot be left to market forces alone, but requires government and civil society-auspiced intersectoral approaches involving agriculture, urban planning, small business, and health sectors. Such approaches must acknowledge complex webs of causation between global and national policies favoring industrialization and private equity, the elimination of food-producing habitats, transformations in food retail, consumer poverty, ignorance, and anxiety.

\section{ACKNOWLEDGEMENTS}

The WHO Centre for Health Development, Kobe, Japan, supported the research contained in the paper. The material on Thailand results from Dr. Dixon's chief investigator role on a Project Grant 268055, Wellcome Trust and National Health and Medical Research Council, "The Thai Health Risk Transition." 


\section{REFERENCES}

1. McMichael P. Development and Social Change. Thousand Oaks, CA: Pine Forge Press; 2004.

2. World Health Organisation. Diet, Nutrition and the Prevention of Chronic Diseases. Joint WHO/FAO Expert Consultation. Geneva: World Health Organisation; 2003.

3. Dixon J, Friel S, Omwega A, Donati K, Burns C, Carlisle R. Theme Paper: The Health Equity Dimensions of Urban Food Systems. Kobe, Japan: Knowledge Network on Urban Settings, WHO Centre for Health Development; 2006.

4. McMichael A. Integrating nutrition with ecology: Balancing the health of humans and biosphere. Public Health Nutr. 2005;8:706-715.

5. Mendez M, Popkin B. Globalization, urbanization and nutritional change in the developing world. Electronic Journal of Agricultural and Development Economics. 2004;1:220-241.

6. Schaefer-Elinder L. Obesity, hunger, and agriculture: the damaging role of subsidies. BMJ. 2005;331:1333-1336.

7. WHO. Obesity and Overweight Fact Sheet No.311. Geneva: WHO; 2006. Available at: http://who.int/mediacentre/factsheets/fs311/en/index.html.

8. Popkin B. Urbanization, lifestyle changes and the nutrition transition. World Dev. 1999;27:1905-1916.

9. Stamoulis K, Pingali P, Shetty P. Emerging challenges for food and nutrition policy in developing countries. Electronic Journal of Agricultural and Development Economics. 2004;1:154-167.

10. Dixon J, Jamieson K. The cross-Pacific chicken: tourism, migration and chicken consumption in the Cook Islands. In: Fold N, Pritchard B, eds. Cross-continental Food Chains. Oxon, UK: Routledge; 2005:81-93.

11. McMichael A, Bambrick H. Meat consumption trends and health: Casting a wider risk assessment net. Public Health Nutr. 2005;8:341-343.

12. Levin C, Maxwell D, Armar-Klemesu M, Ruel M, Morris S, Ahindeke C. Working Women in an Urban Setting: Traders, Vendors, and Food Security in Accra. FCND Discussion Paper No.66. Washington DC: International Food Policy Research Institute; 1999.

13. Wilkinson J. The food processing industry, globalization and developing countries. Electronic Journal of Agricultural and Development Economics. 2004;1:184-201.

14. Hawkes C. Uneven dietary development: linking the policies and processes of globalization with the nutrition transition, obesity and diet-related chronic diseases. Global Health. 2006;2:1-18.

15. Banwell C, Dixon J, Hinde S, McIntyre H. Fast and slow food in the fast lane: automobility and the Australian diet. In: Wilk R, ed. Fast Food/Slow Food. The Economic Anthropology of the Global Food System. Berkeley: AltaMira Press; 2006:219-240.

16. Murdoch J, Miele M. Culinary networks and cultural connections: a conventions perspective. In: Amin A, Thrift N, eds. The Blackwell Cultural Economy Reader. Malden, MA: Blackwell Publishing; 2004:231-248.

17. Sonnino R, Marsden T. Beyond the divide: rethinking relationships between alternative and conventional food networks in Europe. J Econ Geogr. 2006;6:181-199.

18. Donati K. The pleasure of diversity in Slow Food's ethics of taste. Food Cult Soc. 2005;8:228-242.

19. Rozin P. The meaning of food in our lives: a cross-cultural perspective on eating and well-being. J Nutr Educ Behav. 2005;37:S107-S112.

20. Fold N, Pritchard B, eds. Cross-continental Food Chains. Oxon, UK: Routledge; 2005.

21. Fold N. Global cocoa sourcing patterns. In: Fold N, Pritchard B, eds. Cross-continental Food Chains. Oxon, UK: Routledge; 2005:223-238.

22. Pritchard B, Burch D. Agri-food Globalization in Perspective. International Restructuring in the Processing Tomato Industry. Aldershot, England: Ashbury; 2003. 
23. Barling D, Lang T. Trading on health: cross-continental production and consumption tensions and the governance of international food standards. In: Fold N, Pritchard B, eds. Cross-continental Food Chains. Oxon, UK: Routledge; 2005:39-51.

24. Ruel M, Garrett J. Features of urban food and nutrition security and considerations for successful urban programming. Electronic Journal of Agricultural and Development Economics. 2004;1:242-271.

25. World Bank. World Development Indicators. Washington, DC: World Bank; 2004.

26. Ayaga G, Kibata G, Lee-Smith D, Njenga M, Rege R. Policy Prospects for Urban and Periurban Agriculture in Kenya. Urban harvest. Lima, Peru: International Potato Centre; 2005.

27. Neondo H. Kenya-Experts Call for Urban Farming Policy. Canada: Canada's Office of Urban Agriculture. Available at: http://www.ruaf.org; 2002.

28. Flynn K. Food, Culture and Survival in an African City. New York: Palgrave; 2005.

29. NACSOP. Kenya: AIDS in Kenya: Trends, Interventions and Impact, 7th Edition. Ministry of Health (MOH), NACSOP. Kenya: NACSOP; 2005.

30. Maxwell S, Frankenberger TR. Household Food Security: Concepts Indicators Measurement. A technical review. New York: UNICEF, IFAD; 1992.

31. FANTA. Potential Uses of Food Aid to Support HIV/AIDS Mitigation Activities in SubSaharan Africa. Washington, DC: AED; 2000.

32. CBS, MOH, ORC Macro. Kenya Demographic and Health Survey 2003. Central Bureau of Statistics (CBS), Ministry of Health (MOH) and ORC Macro. Calverton, Maryland: CBS, MOH, ORC Macro; 2004.

33. Goss J, Burch D. From agricultural modernisation to agri-food globalisation: the waning of national development in Thailand. Third World Q. 2001;22:969-986.

34. Mundlak Y, Larson D, Butzer R. Agricultural dynamics in Thailand, Indonesia and the Philippines. Aust J Agric Resour Econ. 2004;48:95-126.

35. UNDP. Thailand Human Development Report 2003. Bangkok: United Nations Development Programme (UNDP); 2003.

36. House J. Thailand Retail Food Sector 2000. GAIN report no. TH0116. USA: USDA; 2000.

37. USDA Foreign Agricultural Service. Thailand Product Brief Snack Foods Industry 2004. GAIN report no. TH4082. USA: USDA Foreign Agricultural Service; 2004.

38. Langendijk G, Wellings S, van Wyk M, McComb J, Chusilp K. The prevalence of childhood obesity in primary school children in urban Khon Kaen, Northeast Thailand. Asia Pac J Clin Nutr. 2003;12:66-72.

39. USDA. Australia Organic Products Market Brief. Australian Centre for Retail Studies (ACRS). Canberra: USDA; 2004.

40. Burns C, Jackson M, Gibbons C, Stoney R. Foods prepared outside the home: Association with selected nutrients and BMI in adult Australians. Public Health Nutr. 2002;5:441-448.

41. Dibb S. Rating Retailers for Health. London: National Consumer Council; 2005.

42. Wood B, Wattanapenpaiboon T, Ross K, Kouris-Blazos A. 1995 National Nutrition Survey: Data for Persons 16 Years of Age and Over Grouped by Socio-economic Disadvantage: Executive Summary of the SEIFA report. Melbourne: Monash University, Healthy Eating Healthy Living Program; 2001.

43. AIHW. Australia's Health 2006. Canberra: Australian Institute of Health and Welfare (AIHW); 2006.

44. Burns C, Inglis A. The relationship between the availability of healthy and fast food and neighbourhood level socio-economic deprivation: A case study from Melbourne, Australia. Obes Rev. 2006;7(s2):39.

45. Cameron, AJ, Welborn T, Zimmet P, et al. Overweight and obesity in Australia: the 1999-2000 Australian Diabetes, Obesity and Lifestyle Study (AusDiab). Med J Aust. 2003;178:427-432.

46. Friel S, Broom D. Unequal society, unhealthy weight. In: Dixon J, Broom D, eds. The Seven Deadly Sins of Obesity: How the Modern World is Making Us Fat. Sydney: UNSW Press; 2007. 
47. Fischler C. Food, self and identity. Soc Sci Inf. 1988;27:275-292.

48. Banwell C, Hinde S, Dixon J, Sibthorpe B. Reflections on expert consensus: a case study of the social trends contributing to obesity. Eur J Pubic Health. 2005;15:564-568.

49. World Health Organization. The Informal Food Trade. Fact Sheet 3. Africa: Food Safety Unit, Regional Office for Africa, World Health Organization. Available at: www.afro.who.int/des.

50. FAO/WHO. Global Forum of Food Safety Regulators. In: Proceedings of the Second FAO/WHO Forum on Food Safety Regulators, Bangkok, Thailand, 12-14 Oct 2004. Bangkok, Thailand: FAO/WHO; 2005.

51. Frumkin H, Frank L, Jackson R. Urban Sprawl and Public Health. Designing, Planning and Building for Healthy Communities. Washington: Island Press; 2004.

52. Rozin P, Fischler C, Imada S, Sarubin A, Wrzensniewski A. Attitudes to food and the role of food in life in the USA, Japan, Flemish Belgium and France: Possible implications for the diet-health debate. Appetite. 1999;33:163-180.

53. Nestle M. Food Politics. Berkeley: University of California Press; 2002.

54. Buttel F. Some observations on agro-food change and the future of agricultural sustainability movements. In: Goodman D, Watts M, eds. Globalising Food. London: Routledge; 1997:344-365. 